\title{
Entrevista: Ruy Guerra cidadão de várias pátrias, passageiro de diferentes revoluções ${ }^{1}$ \\ Ruy Guerra: citizen of many homelands, passenger of different revolutions
}

\begin{abstract}
Rita Chaves e José Luís Cabaço*
uy Guerra nasceu, nos anos 30, em Moçambique, em Maputo, na época Lourenço Marques, a capital da então colónia africana de Portugal no Oceano Índico. Enraizada na consciência crítica do regime colonialista e ditatorial, sua postura rebelde o força a emigrar. Depois de uns meses em Portugal, vai para a França onde se forma como cineasta, em meio a um ambiente de grande debate que tem como uma de seus marcos a revolução estética que gerou a Nouvelle Vague. No final dos anos 50, vem para o Brasil e reformula essa experiência nas condições de um país periférico. Seu profundo empenho social e a qualidade de seu trabalho o transformariam numa das referências do Cinema Novo. Durante os anos sombrios da ditadura, trabalha em Cuba, em Portugal. E participa do nascimento do cinema da terra em que nasceu que, em 1975, tinha proclamado a independência. Nesse raro roteiro de deslocamentos, Ruy Guerra faz cinema, teatro, escreve letras de música, publica crónicas, é professor, planeja escrever um romance... Estamos diante de alguém que pode ser visto como um passageiro de várias e diferentes revoluções. Sobre essa vida tão multifacetada, ele nos fala nessa entrevista.
\end{abstract}

1. Agradecemos muito a colaboração fundamental da Profa. Dra. Vavy Borges, da UNICAMP.

* Universidade de São Paulo (USP), São Paulo-SP, Brasil / Universidade Técnica de Moçambique, Maputo, Província de Maputo, Moçambique. E-mail: rita.chaves@uol.com.br / jlcabaco@hotmail.com. 
Rita Chaves e José Luís Cabaço Você nasceu em Moçambique, na África, onde viveu 19 anos antes de partir para a Europa. Qual a importância que atribui a esse fato?

Ruy Guerra Como sempre disse, considero que esses anos formaram a base daquilo que sou. A experiência da minha infância e juventude vividas em Moçambique foi muito forte. Foi na África, primeiro por caminhos afetivos e depois por empenho político, que se construiram os fundamentos daquilo que sou como ser humano. Ali fui tomando consciência do racismo e da dominação colonial. O lugar onde a gente nasce deixa uma marca forte. Em Moçambique fiz minhas primeiras discussões políticas, li os primeiros textos, militei com outros companheiros, tive a primeira experiência da repressão de uma ditadura. Esses anos ajudaram-me naquilo que depois foi a minha formação ideológica e as experiências que vivi depois da minha partida vieram enriquecer os valores essenciais aprendidos no contexto da família e na realidade colonial. Depois do período que vivi no meu país de origem já independente, compreendi que as trajetórias são outras e que já teria dificuldade de me adaptar. Ainda recentemente passei duas semanas no país, a convite do festival de cinema local, atravessei a fronteira para a África do Sul, viajei um pouco, revi amigos, e as emoções foram muito intensas. Continuo a sentir-me um africano de base, hoje um latino-africano.

R. C. E J. L. C. Depois de uma breve passagem por Portugal, rumou para França para estudar cinema. Onde nasce sua paixão pelo cinema? Já vinha em sua bagagem?

R. G. O cinema entrou em minha vida aos poucos, ainda em Moçambique. Assiti quase que toda produção hollywoodiana e britânica que chegava a Lourenço Marques através da África do Sul. Escrevi para jornais críticas sobre alguns desses filmes. Fiz um filme com uma câmera emprestada sobre as dificeis condições de vida dos trabalhadores do porto. Mas eu queria mesmo era ser escritor, só que escritor não era profissão. Assim, saí de Moçambique e passei por Portugal já a caminho da França. Estudar cinema era uma forma de sair do mundo colonial e do salazarismo. Na Europa, havia três escolas de cinema: havia a escola de Lodz, na Polônia, mas o curso era de seis anos e eu tinha de aprender polonês, o que não era fácil; alternativa aliciante era Roma, mas os estrangeiros eram aceites na Cinecittà apenas como alunos assistentes 
e não tinham acesso à prática; optei então pelo IDHEC, em Paris. Foi um período interessante e que muito me marcou. Os jovens cineastas contestavam a indústria cinematográfica e o debate era muito intenso.

R. C. E J. L. C. Fale-nos um pouco desse momento da sua formação como cineasta.

R. G. Havia na época dois grupos de jovens cineastas que se organizavam em torno de duas revistas: os Cahiers du Cinéma e a Positif, que era de esquerda e da qual acabei me tornando próximo. Ambos os grupos se contrapunham à indústria cinematográfica francesa tradicional, um cinema industrial. Defendiam uma estética nova, propunham o cinema de autor. Mas mantinhamos uma discussão com o pessoal dos Cahiers sobre a abordagem política. Eles tratavam problemas típicos da burguesia: era o cinema dos Champs Elysées, dos dramas pessoais, dos triângulos amorosos entre gente sofisticada. Alguns dos nomes mais conhecidos do grupo dos Cahiers eram o Truffaut, o Chabrol, o Eric Rohmer. A Nouvelle Vague, dominada por esta visão elitista, concentrou suas preocupações em Paris.

Até a Segunda Guerra, o cinema francês tinha uma tradição voltada para as coisas populares. Nos filmes de Renoir, Carné, Clement e outros havia camponeses, os operários, a gente comum, marginais... O grupo da Positif procurava ligar a revolução estética e o cinema de autor a esta tradição. Se o cinema francês ganhou no plano estético, ele perdeu na ligação com os problemas do país real. Essa vivência e o debate que a acompanhou foram sem dúvida importantes na minha formação, mas eu me considero à margem daquilo que ficou conhecido como a Nouvelle Vague.

R. C. E J. L. C. Em poucos anos, entre 1952 e 1958, você sai de Moçambique, passa por Portugal, vive uns anos na França, uns meses na Grécia. E vem para o Brasil. Como você vê essa errância?

R. G. Eu me vejo como um produto típico do subdesenvolvimento. Eu nasci em Moçambique, uma colônia portuguesa. Era considerado português mas de segunda classe. Nem sequer tinha uma cidadania plena, pra ir a Portugal tinha que ter passaporte. Os dissidentes do Império português eram mandados para lá. Tomás Antonio Gonzaga, grande poeta da Inconfidência Mineira, por exemplo, foi um deles. O meu é o périplo de um imigrante, e o imigrante 
é um tipo de degredado. Ninguém imigra se está bem no seu país de origem. Sai por razões economicas e politicas, pois não tinha espaço para realizar aquilo que queria dentro do meu país. Ao longo do tempo fui exercendo essa não nacionalidade. Eu nasci sem nacionalidade e fui buscando uma nacionalidade que não encontrei até hoje, porque nacionalidade não se adquire.

R. C. E J. L. C. E deixa Paris, um ambiente de grande efervescência cultural, onde havia um debate muito sofisticado e vem para o Brasil. Não foi muito difícil adaptar-se?

R. G. Como eu dizia, nacionalidade não se adquire, nacionalidade tem uma coisa que é muito visceral, irracional, que normalmente está associada ao lugar onde se nasceu. É o cheiro, o clima, é uma coisa muito primitiva, animal. Eu encontrei esses cheiros, essa animalidade no Brasil. O paralelo do Rio de Janeiro é o mesmo da minha cidade natal. Ao mesmo tempo, há o mesmo idioma, a presença forte da cultura portuguesa e, evidentemente, a mesma matriz lusitana. Minha geração, e outras que vieram depois, tivemos na arte e na literatura brasileira um ponto de encontro. Eu comecei a ler os clássicos portugueses ao mesmo tempo que lia os brasileiros. Li Alexandre Herculano e Eça de Queirós juntamente com Graciliano Ramos e Guimarães Rosa. A minha formação cultural é uma formação especificamente híbrida, que mistura duas culturas, duas vertentes, independetemente da intermiscigenação que existe entre elas. Dentro dessa placenta cultural, quando eu cheguei aqui e encontrei o mesmo clima, as mesmas frutas, a mesma paisagem humana, eu me senti na minha terra natal. Era qualquer coisa de diferente, mas muito próxima.

R. C. E J. L. C. No Brasil, você participa de novo movimento revolucionário no cinema. Viveu-o como uma ponte com a experiência francesa ou percebeu sentidos novos porque o fenômeno se dava num país com menos recursos do que a França e onde o cinema tinha menos espaço?

R. G. O Cinema Novo tem em comum com a experiência francesa apenas a contestação à indústria cinematográfica. Foi um movimento que criou espaços próprios de produção o que implicou, na esmagadora maioria dos casos, a necessidade de se fazerem filmes com orçamentos e recursos também limitados. O Cinema Novo era uma experiência muito diferente do ponto de vista político e estético. Inspirava-se e dirigia-se às classes populares, procu- 
rava sair das grandes cidades e procurar o povão lá onde ele vivia, tratando seus problemas. Procurava-se apresentar e representar o Brasil, olhando a sua realidade. Os personagens são populares do Rio de Janero, do Nordeste, da própria São Paulo. O país não era só futebol, samba e mulatas e era preciso dar expressão à vida, aos problemas e às contradições que o povo vive. No Brasil o movimento era caracterizado por um discurso político, que sempre foi uma das minhas preocupações.

Optei por um discurso histórico que, sendo político, abria sobre trajetórias mais amplas. No Cinema Novo a urgência do quotidiano sobrepunha-se às dificuldades financeiras e às limitações técnicas. Não se deixava de fazer cinema por falta de recursos, mas, nos condicionalismos em que se vivia, fazia-se cinema com grande preocupação estética e buscando novos caminhos. Não havia escola de cinema no Brasil e, por isso, os jovens cineastas de então eram apaixonados autodidatas, que mais tarde, os que puderam, foram complementar a sua formação junto de outras cinematografias. Nós íamos fazendo e aprendendo uns com os outros; havia uma grande troca de informação e todos, quando solicitados, ajudavam. O debate cultural era intenso. Vivia-se um momento de grande entusiasmo, uma grande euforia nacional do periodo juscelinista. Havia uma grande esperança e naqueles anos a esperança era uma quase certeza. Tudo podia acontecer. Embora muitos dos que estavam ligados ao Cinema Novo não estivessem preocupados com uma prática política, a maioria estava voltada para um cinema idelogicamente oposto à mentalidade aburguesada da Nouvelle Vague. Em comum, tinham todos a defesa da não submissão a uma prática cinematográfica industrial.

R. C. E J. L. C. Você e a maior parte dos seus colegas trabalhavam em condições financeiras, técnicas e pessoais muito difíceis. Essas dificuldades refletiram-se também nas opções estéticas?

R. G. No início da década de sessenta não havia no Brasil uma indústria cinematográfica como na França. Sentiamos que eramos parte de uma luta que nos pedia dedicação. A vida pessoal vinha depois. Meu primeiro longa metragem, Os Cafajestes, foi produzido por uma cooperativa de que nós, director, produtor, atores, técnicos fazíamos parte. Foi programado para ser todo filmado durante o dia, porque não tinhamos meios de filmar à noite. As cenas noturnas eram filmadas de dia com um filtro. No laboratório, algumas 
cenas não resultaram e arrumámos alguns refletores. Só que eram tão poucos que os atores não se podiam quase movimentar para não sair do campo de luz. Os recursos eram mínimos, a equipe era pequena, mas caprichámos na qualidade da fotografia, na música, na linguagem. Tinhamos as nossas concepções estéticas mas era na dialética entre elas e os escassos recursos que a nossa criatividade encontrava as melhores soluções

R. C. E J. L. C. Com pouco tempo de Brasil, você faz "Os Fuzis", um filme que, sem dúvida, capta aspectos fundamentais da história e da identidade brasileiras. Foi a vivência moçambicana que ajudou ou foi a percepção aguda de um olhar que se recusa a naturalizar o que vê?

R. G. Os Fuzis é o resultado de uma pesquisa quase obsessiva, de um estudo muito minucioso e atento. $\mathrm{O}$ subdesenvolvimento era familiar ao meu mundo, mas apercebi-me logo que aquele subdesenvolvimento tinha especificidades que eu tinha de conhecer e interiorizar. Falei com todo tipo de pessoas, li tudo o que consegui pegar. Fiz um enorme esforço para entrar e interpretar aquela realidade e parece que consegui. A experiência que tinha do colonialismo e do subdesenvolvimento foi sem dúvida um fator que removeu alguns obstáculos e me abriu caminhos para mais rapidamente me apropriar de elementos importantes para enfrentar o desafio.

R. C. E J. L. C. A ditadura viria restringir bastante a liberdade dos cineastas, todavia você ainda conseguiu dirigir alguns filmes muito importantes. Como um intectual independente e revolucionário se relaciona com o poder político repressivo e reaccionário?

R. G. Essa é uma questão que sem dúvida se relaciona com a estética da produção artística.

Criar numa sociedade com censura não me tira a motivação. Exige sim uma reformulação em termos sensoriais, em termos do próprio discurso. Os filmes naquele período foram feitos tentando driblar a censura; era um cinema de metáforas visuais. Mas há sempre o perigo, neste exercício, de se construir um discurso codificado que exige um público que domine as chaves de interpretação. Doutro modo, o recurso passa despercebido e, portanto, sem significado. O equilíbrio requer grandes cuidados com a linguagem e com o tratamento que se dá ao tema. Não se pode abstrair o significante do significado. 
Em geral nas ditaduras os apoios oficiais são poucos e muito direcionados e os meios de produção restritos.

R. C. E J. L. C. Você trabalhou depois em países, como Cuba e Moçambique, onde os projetos nacionais entravam, por vezes, em conflito com a liberdade do artista. Viveu essas experiências como uma repetição do que tinha experimentado sob a ditadura brasileira?

R. G. São coisas diferentes, pelo menos na experiência que eu tive. Ao contrário da ditadura brasileira, nesses países, no período em que lá vivi, a política dos governos em relação ao cinema era de grande incentivo à produção. Os recursos eram escassos porque os países eram pobres, mas havia grande vontade política e as iniciativas eram apoiadas. Os projetos nacionais eram muito importantes e os cineastas, pelos menos aqueles com quem privei, estavam envolvidos com grande entusiasmo. É verdade que pairava por vezes uma certa atmosfera de dirigismo, mas é preciso pensar que inventar e construir o futuro precisa de reflexão e de objetivos. E nem sempre se consegue um equilíbrio. Havia hesitações e indefinições, faziam-se muitas reuniões porque as ideias novas eram submetidas a discussão, o que em certos casos atrasava a conclusão dos projetos. Por vezes pensava que tinha que esperar um pouco para compreender melhor as questões que estávamos a enfrentar e isso sempre me pareceu uma coisa natural. Os problemas em Maputo, quando surgiam, eram mais com os burocratas da cultura do que com os dirigentes políticos. Os burocratas da cultura tendem ao conservadorismo, receiam o que é diferente, o novo. Não compreendiam, ou não queriam compreender, que estávamos descolonizando e procurando um novo conteúdo de classe para as coisas que fazíamos. Era necessário contornar esses burocratas temerosos e reacionarios e ir diretamente ao topo. Havia discussão e havia crítica e decisões com as quais não concordavamas cuja aceitação não me violentava. Em Cuba simplesmente não tive pr oblema com a censura. Procurei colocar-me sempre ao lado de maior independência para a produção, para seus artistas.

R. C. E J. L. C. Em 1975 a sua terra natal tornou-se independente, com um projeto político progressista. Você correu para estar presente na cerimônia da independência e logo se disponibilizou a apoiar o nascimento de um cinema moçambicano. Ali acabaria por realizar, com os meios precários disponíveis, 
diversos documentários e uma longa metragem, "Mueda, Memória e Massacre". O que representou para si, como moçambicano, como intelectual revolucionário, como cineasta essa experiência?

R. G. Foi uma experiência emocional muito forte. Em primeiro lugar, existia a emoção de voltar à terra onde nasci e de ver realizada independência, que era um sonho da minha adolescência. Depois, havia essa sensação inédita de participar no nascimento de uma cinematografia. Trabalhei num projeto de cinema móvel, percorrendo todo o país e levando o cinema a quem nunca tinha visto. Esse projeto passou a uma segunda fase, a da criação de salas de cinema em áreas rurais. A população construiria com materiais locais, as salas fechadas ou abertas, para as projeções. O Instituton Nacional de Cinema INAC forneceria os equipamentos (incluindo os geradores elétricos, pois não havia luz nas aldeias comunitárias) e faria chegar os filmes. Cosnstruiram-se algumas destas salas, mas nesta fase o projeto foi interrompido por razões diversas que desconheço, entre elas, a guerra civil. Minha contribuição foi, sobretudo, uma colaboração para preparar o nascimento de um cinema verdadeiramente moçambicano. Convidei vários amigos do cinema, brasileiros e não só, para dar cursos nas várias áreas. Foram sem remuneração, somente pelas passagens e alojamento, que o Instituto garantia. O debate era, então, muito apaixonado. Discutia-se sobre tudo, tudo estava em questão, mas as preocupações dominantes e o debate mais veemente eram sobre as opções a fazer com os meios técnicos precários e na linguagem apropriada para comunicar com o povo, pouco ou nada familiarizado com o cinema. Os jovens que foram formados nesse contexto são hoje quem garante a produção cinematográfica do país. Fui encontrá-los na visita que fiz recentemente a Moçambique.

Nos quase dois anos vividos em Moçambique reencontrei as minhas raízes mais profundas, emocionei-me com o generoso entusiasmo que reinava, mas descobri também que, apesar da forte relação afetiva que me ligava a Moçambique, os 30 anos de exílio tinham determinado trajetórias diferentes, da minha vida e do país onde nasci.

R. C. E J. L. C. Em seu ofício, você tem transitado por muitas áreas: a poesia, a canção, o teatro. Na escrita, a crônica também o motivou. Percebe-se aí uma outra forma de errância. 
R. G. É outra resultante do subdesenvolvimento. Se eu tivesse nascido norteamericano, felizmente não nasci, mas se tivesse nascido seria possivelmente um diretor de cinema de sucesso, e teria sido só diretor. Poderia viver desse trabalho. Como em certos países, e não só no Brasil, não se pode ser só cineasta, porque são países de uma economia que ainda não possui essa sustentação, fui obrigado a inventar modos de sobreviver. Quando se é obrigado a emigrar ficamos feito gafanhotos, pulando de um lado para o outro. Mas sempre o fiz em atividades ligadas à imagem e à palavra, que considero minha primeira e última trincheira. Isso faz criar contatos, amizades, espaços. Virei letrista, cronista, trabalho em teatro. Procurei atividades que achava que não me desviavam do meu rumo. Não me agrada essa imagem do talento plivalente. Fui empurrado pelas circunstâncias do subdesenvolvimento, que pode nos levar a descobrir novas possibilidades, novos caminhos.

R. C. E J. L. C. A sua atividade na área do ensino também pode ser vista nesse quadro? Como aparece no Ruy essa preocupação com a mudança, com a renovação que o mobilizou como cineasta?

R. G. Na minha experiência universitária, como diretor, montei um curso pluralista, para formar em diferentes áreas: direção, produção, montagem, roteiro, fotografia... Como o pessoal tem pouca base técnica, projetei um curso de formação, com cursos de história: do cinema brasileiro, do cinema mundial, da arte. O que percebi é que estavam ali faixas etárias muito diferenciadas, alunos desde os 18 aos 60 anos. Alguns já com carreira, outros querendo mudar para a área de direção. O que considero fundamental é fazê-los pensar o cinema e pensar a vida, refletir sobre o seu posicionamento político dentro da vida. Este pensamento está vinculado ao ato de filmar. Defendo sempre que a linguagem não se copia, se cria. Meu interesse é ensinar a pensar a linguagem e porque ela se formou, em que medida ela é válida e como é que se pode romper com ela. Desde que integrados num projeto próprio de linguagem, todos os rompimentos são legítimos. Eu abro as portas. Há os que vão, há os que ficam no limiar da porta. Preocupo-me em formar a cabeça.

R. C. E J. L. C. De várias maneiras a literatura tem estado presente na sua vida. $\mathrm{Na}$ adaptação de obras literárias para o cinema, no exercício da crônica. 
Nota-se um namoro com a literatura constante. Essa pode ser uma relação ainda mais intensa?

R. G. Quando era jovem, eu queria ser escritor. Já escrevi contos. Durante cinco anos escrevi uma crónica semanal para o Estado de São Paulo. Mas ainda vou ser romancista. Tenho um romance que comecei a escrever e que espero retomar. Mas ainda não é esse. Isso são só ensaios que venho fazendo. Estou esperando o momento oportuno. Tenho um ou dois temas que quero desenvolver. Escrever é um ato doloroso, é um ato solitário, é um ato que tem de ir buscar muito longe. Quando você vê a coisa pronta é um prazer enorme, mas até lá é muito duro, exige muito tempo.

Tenho muitos amigos escritores e sempre pergunto: quanto tempo você leva para escrever um livro? Quanto produz por dia? E as respostas sempre foram muito desencorajadoras. Por exemplo, com o Gabriel Garcia Marquez. Ele me tinha dito que estava escrevendo um romance há quatro anos. Um dia me telefonou de Barcelona e disse: Ruy, acabei!. Eu estava em Paris e respondi: Oba! Quando é que eu leio o livro? Quando é que vai ser editado? E ele respondeu: Eu vou botar o livro na gaveta e daqui por um ano eu vou ler. Com mais uns três meses de correção, ele fica pronto! Outra vez passei pelo México, onde ele estava residindo. Ele estava escrevendo a novela Do amor e outros demónios. Fui à casa dele jantar e perguntei: Como vai a novela? Ele respondeu Quase pronta. Já estou nas correções. Aí disse para a mulher Mercedes, a quem ele chama Mexe: Mexe, me faz um favor? Traga aí a última correção em que estou trabalhando. Quero mostrar ao Ruy" Ela trouxe e ele mostrou-me: Esta é a correção que estou fazendo. Vinha escrita em computador e eu folheei até aí a página 15. Estava tudo praticamente reescrito a caneta. Ele percebeu a minha perplexidade e disse: Esta é a quinta revisão. Passados uns dois anos voltei a encontrar com ele e perguntei: Lembra daquele jantar em sua casa? Lembra que me mostrou a quinta revisão de sua novela? E ele respondeu: Lembro. E depois dessa ainda foram mais umas dez. E iguais. Eu comecei a tentar escrever desde adolescente. O avanço é muito lento. É preciso tempo. Então a minha eventual carreira de escritor, que era a minha primeira vocação e a que eu quero cumprir, ainda está começando.

R. C. E J. L. C. Você tem um percurso raro, com uma impressionante multiplicidade de experiências, em vários contextos marcados por algum tipo 
de revolução. Ouvindo-o falar em diferentes ocasiões, apercebemo-nos que você é uma pessoa que reflecte profundamente sobre o vivido. Como vê, de acordo com essa rica experiência, o papel da cultura no processo de transformação progressista das nações?

R. G. Um processo é revolucionário quando promove a redistribuição da riqueza social e cria condições para uma satisfação de existir. Isso implica uma reformulação dos valores, uma transformação cultural. Numa sociedade dominada pelas oligarquias, sejam elas linhageiras, económicas ou burocráticas, a cultura popular existente tem tendência a ser anquilosada em formas folclóricas não atuantes. Teoricamente, elas ficam sendo apresentadas como cultura exótica dentro do próprio país.

A revolução implica um processo de transformação. A cultura deve ser agente desse processo no qual as velhas formas serão substituídas por formas novas que determinam e são criadas por um novo olhar, uma nova realidade. Não há uma verdadeira revolução, se não se desconstroem as velhas formas, se não se descodificam os sistemas herdados, os padrões estéticos (que são padrões ideológicos), abrindo espaço para que despontem novos códigos, outros signos, uma linguagem própria, modos de expressão alternativos, correspondendo às relações sociais que se estão estabelecendo. É preciso que nasça e se consolide uma nova cultura, emanada das classes sociais emergentes, que com elas mantém intimidade e onde elas se reconheçam. Essa sim é a cultura que vai consolidar a realidade estrutural que se está afirmando.

A experiência do chamado socialismo real é muito significativa. Os burocratas da cultura venceram. Por comodismo, por carreirismo e porque se afastaram das massas populares ficaram esclerosados; os burocratas da cultura criaram obstáculos às ideias e iniciativas que propunham questionar a realidade para avançar e favoreceram a política de preencher as formas "que todo o mundo usa”. Mais uma vez se provou que a forma tem uma essência ideológica e é, portanto, indissociável do significado. O sistema capitalista continuou a ser culturalmente hegemônico e a falta de uma resposta por parte dos países que se queriam revolucionários acabou por produzir subculturas desse sistema.

Recebido em 10 de maio de 2012 e aprovado em 19 de junho de 2012. 